\title{
Comunicação em saúde no Hospital Universitário Regional de Maringá
}

\section{Health communication at Maringá Regional University Hospital \\ Comunicación de salud en el Hospital Universitario Regional de Maringá}

\author{
Ana Paula Machado Velho \\ Jornalista do Hospital Universitário Regional de Maringá, Profa. Dra. em \\ Comunicação e Semiótica. Orientadora do Trabalho Hospital Universitário \\ Regional de Maringá - PR \\ https://orcid.org/0000-0001-9423-6716 \\ anapaula.mac@gmail.com
}

Tiago Franklin Rodrigues Lucena

Professor Dr. do Curso de Comunicação e Multimeios da Universidade Estadual de Maringá. Possui experiência com Promoção da Saúde e Arte Socialmente Engajada Universidade Estadual de Maringá - PR

$$
\begin{aligned}
& \text { http://lattes.cnpq.br/7804682618173184 } \\
& \text { https://orcid.org/0000-0002-0154-7417 }
\end{aligned}
$$

tiagofranklin@gmail.com

\section{Débora Cristina Arcanjo}

Possui graduação em Jornalismo pela Faculdade Maringá (2016). Atualmente é Residente em Jornalismo da Universidade Estadual de Maringá. Universidade

Estadual de Maringá - PR

$$
\begin{gathered}
\frac{\text { http://lattes.cnpq.br/6598504804525841 }}{\text { https://orcid.org/0000-0002-0886-8379 }} \\
\text { acnj.deh63@gmail.com }
\end{gathered}
$$

\section{Sônia Cristina Soares Dias Vermelho}

Doutora em Educação: História, Política, Sociedade, Pontifícia Universidade Católica de São Paulo (PUC/SP). Professora da UFRJ no Programa de PósGraduação em Educação em Ciências e Saúde vinculado ao Núcleo de Tecnologia Educacional para Saúde - NUTES, no Laboratório de Linguagens e Mediações - Universidade Federal do Rio de Janeiro - RJ

http://lattes.cnpq.br/4403086334271874

https://orcid.org/0000-0003-2205-8070

cristina.vermelho@gmail.com

\section{Lara Beatriz Natalie Arantes}

Estudante do curso de Comunicação e Multimeios - Universidade Estadual de Maringá - PR

lara.beatrizn07@gmail.com 
Resumo: O artigo relata o processo de organização do Setor de Comunicação do Hospital Universitário Regional de Maringá (HUM) da Universidade Estadual de Maringá-PR, detalhando as informações que subsidiaram a elaboração de um projeto de comunicação e educação em saúde. Para a discussão, o fio condutor foi a analise dos caminhos que levaram a produção do programa "Sintonia HUM" vinculado na rádio UEM-FM e em redes sociais on-line: Facebook. O programa ajuda a promover a importância do Hospital como unidade de assistência exclusiva do Sistema Único de Saúde (SUS) e como hospital-escola. Dados de acesso aos conteúdos nas redes sociais e feedback da comunidade indicam um estreitamento positivo entre a Instituição e seu público-alvo, tornando-os parceiro na disseminação de informações positivas, produzidas pela equipe

Palavras-chave: Comunicação em Saúde. Educação em Saúde. SUS. HUMMaringá.

Abstract: The article reports the organization process of the Communication Sector of the Public Hospital of Maringá (HUM) of the University of MaringáPR, detailing the information that supported the creation of a project of health education and communication. For the discussion, we analyse the paths that led to the production of the program "Sintonia HUM" to UEM-FM radio and available online on Facebook. The program helps to promote the importance of the hospital as an exclusive care unit of the Brazilian Health System (SUS) and as a school-hospital. Data access to interaction on Facebook provides us with some community feedback indicating a positive narrowing between the institution and its target audience, making them as partner in the dissemination of positive information produced by our team.

Keywords: Health Communication. Health Education. Health System. HUMMaringá.

Resumen: El artículo informa el proceso de organización del Sector de Comunicación del Hospital Universitario Regional de Maringá (HUM) de la Universidad Estatal de Maringá-PR, detallando la información que apoyó la elaboración de un proyecto de comunicación y educación en salud. Para la discusión, el hilo es el análisis de los caminos que condujeron a la producción del programa "Sintonia HUM" vinculado en la radio UEM-FM y las redes sociales: Facebook. El programa ayuda a promover la importancia del hospital como unidad de atención exclusiva del Sistema Único de Salud (SUS) y como hospital ensino. El acceso a los datos del contenido en las redes sociales y los comentarios de la comunidad indican un estrechamiento positivo entre la 
institución y su público, lo que los convierte en socios en la difusión de información positiva producida por el equipo.

Palabras clave: Comunicación en salud. Educación en salud. SUS. HUM-Maringa.

O ambiente hospitalar é historicamente associado a um espaço de dor, de exclusão e para onde são encaminhados os doentes (ORNELLAS, 1998). No atual contexto economico, há também uma mercantilização da doença, onde serviços de saúde se tornam oportunidade de negócio. No entanto, um hospital público que atenda ao Sistema Único de Saúde - SUS deve seguir lógica diferenciada.

No atual cenário, onde o SUS é frequentemente representado como ineficiente pela mídia (OLIVEIRA, 2000), a relação com a imprensa se torna um duplo desafio. Se por um lado a comunicação pública de um hospital deve desmistificar a visão dele como sendo um espaço exclusivo da doença e dor, por outro deve enfrentar os interesses da desmonte do serviço publico de saúde com viés neoliberal (SOARES, 2000).

A dimensão da comunicação de um hospital, além de lidar com esses contextos sócio-politicos, deve também informar a população em temas sensíveis de saúde pública. O panorama da comunicação em saúde que se desenha atualmente é de um ambiente com diversas fontes de informação, e em muitos casos, notícias falsas que impactam negativamente a saúde coletiva (MERCHANT; ASCH， 2018; WASZAK; KASPRZYCKA-WASZAK; KUBANEK, 2018). Essas informações encontram condições de circulação nos novos espaços midiáticos, em especial, nos aplicativos de conversa como WhatsApp e redes sociais on-line (Facebook, Twitter, Instagram). Cita-se por exemplo, como uma consequencia desse fenomeno, a desconfiança frente a eficácia das vacinas (CLIFT; RIZZOLO, 2014; GREENBERG; DUBÉ; DRIEDGER, 2017), a recusa de aderir a certos tratamentos e a crença em teorias conspiratórias (WOOD, 2018). Soma-se a isso a queda no consumo de informações sobre ciência e tecnologia nas mídias tradicionais e que, $88 \%$ dos indíviduos não se lembram ou não sabem indicar instituição de pesquisa científica, nem mesmo universidades ${ }^{1}$ (CGEE, 2019). 
Assim, estabelecer uma comunicação científica de qualidade sobre o tema da saúde é essencial e urgente para a sociedade, que ainda se adapta e aprende sobre o potencial dos novos meios de comunicação. Mas diferente de criar um veículo e conteúdos voltados para especialistas, a necessidade é de se pensar em produções que proponham uma aproximação com a população em geral, mais sensíveis as informações falsas sobre saúde, em plataforma digital e com maior abragência. Esse artigo descreve os desafios e etapas enfrentadas na criação de estratégias de comunicação em saúde de um hospital público no sul do país, descrevendo nessa oportunidade, um produto vinculado principalmente nos canais nas redes sociais online.

\section{Comunicação em Saúde de Hospital}

O Hospital Universitário Regional de Maringá (HUM), ao longo de 30 anos de vida se consolida enquanto instituição voltada ao ensino, à pesquisa e à assistência em saúde, sendo referência para região de Maringá no Paraná, onde vivem cerca de 2 milhões de habitantes. O HUM faz parte do Sistema Único de Saúde (SUS), exclusivamente, o que dá a ele um peso significativo quando se fala em assistência à população e sobre a responsabilidade de ação em casos de urgência e emergência. O HU atende pessoas das comunidades vulneráveis, tratando vários tipos de patologias, muitas vezes, provocadas por maus hábitos adotados no cotidiano. Devido a isso, além da assistência, a instituição visa a formação de profissionais e não desconsidera a importancia da dimensão da comunicação e educação em saúde.

Tendo em vista a natureza do hospital, as estratégias de comunicação devem levar em consideração todas as dimensões locais, público interno e externo, e os veículos de comunicação disponíveis. Sobre a importancia da comunicação em saúde lembramos que o uso dos meios de comunicação já são incorporados como ferramenta para acesso a informações sobre o tema, tanto por profissionais quanto por usuários dos serviços (MACHADO, 2007). Para o autor, ainda importa articular as ações de comunicação em saúde como elementos produtores do saber coletivo levando a autonomia e emancipação do indivíduo no seu próprio cuidado. Mas o 
cenário midiático atual, insere novos veículos de comunicação, e apesar da relevancia dos meios de comunicação de massa impera, nessa atual fase, a intensificação dos ambientes de saúde no uso de redes sociais online como canais alternativos de comunicação, tendência já observada em outros países (GRIFFIS et al., 2014; MOORHEAD et al., 2013). No entanto, verifica-se que as instituições hospitalares que mais usam das redes sociais on-line são de carater privadas e consideram as redes com uma perspectiva de um "marketing hospitalar" (SMITH, 2017), promovendo a marca da instituição ou como demonstrou Gonçalves (2017), se valendo das redes sociais de forma pouco dialógica.

Dessa maneira, incluir nas ações do HUM iniciativas de promoção da saúde, por meio de estratégias de educação e comunicação, articulando veículos de comunicação de massa com redes sociais on-line pode reforçar a importância do Hospital como peça chave do sistema público de saúde da região. Ao mesmo tempo busca-se apoiar a concretização de todos os princípios do SUS, que vão da assistência em nível público, passando pela oferta de informação à população e chegando à garantia da saúde integral do cidadão (BRASIL, 1988). Cabe lembrar que o SUS é constantemente referenciado como ineficiente, em produções jornalísticas que focam na polêmica e criam uma visão limitada e negativa do SUS, gerando desconfiança e a impossibilidade de melhorar o Sistema (OLIVEIRA, 2000; SILVA; RASERA, 2013).

\section{Comunicação e Educação em Saúde em Hospitais}

O conceito de educação em saúde está ancorado no universo da promoção da saúde (BRASIL et al., 2015). Este reúne uma série de processos que tem como objetivo fomentar a participação da população em ações cotidianas que lhes garanta qualidade de vida. Essa noção está baseada em um conceito que considera saúde como um estado positivo e dinâmico de bem-estar, que integra os aspectos físicos e mentais (ausência de doença), ambiental, pessoal e social (MACHADO et al., 2007).

No entanto, para que se possa propor uma ação em educação e comunicação em saúde, se fez necessário planejamento. Esta é a primeira vez 
que a equipe do HUM conta com uma estrutura de comunicação que pode realizar um projeto desta dimensão. Para o projeto de comunicação, partiu-se do princípio de que era necessário pensar ações de comunicação que dessem suporte a ações de educação em saúde, levando informações para o usuário, de forma que ele pudesse: conhecer o SUS, seus direitos e deveres diante do Sistema; saber como o HUM se encaixa neste universo; e agir para ter melhor qualidade de vida. Além disso, essa iniciativa deveria esclarecer o público interno (servidores e acadêmicos) sobre aspectos que fortalecem a participação deles no cenário da saúde pública no Brasil.

A necessidade de se discutir comunicação no âmbito da saúde é, de certa maneira, recente. $\mathrm{Na}$ área da saúde coletiva, essa necessidade vem se tornando crescente a partir do nascimento do SUS, em 1988. O Sistema possui suas raízes na VIII Conferência Nacional de Saúde, realizada em 1986, quando se propôs a garantia do direito à informação, para reforçar a participação social na fiscalização de serviços e formulação de políticas públicas.

Segundo Araújo e Cardoso (2009), o campo da Comunicação e Saúde (C\&S) surgiu a partir desse cenário de construção do SUS e se fortaleceu à medida que as Conferências Nacionais de Saúde (CNS) foram se solidificando na agenda dos movimentos sociais. Nesse cenário, as dimensões da promoção, educação e comunicação são essenciais.

Para França (2003, p.1), a educação em saúde se baseia neste processo de diálogo entre as pessoas. Já Padro, Santos e Cubas (2009) dizem que essa área concebe o indivíduo como o principal responsável por sua realidade. “Como tal, suas necessidades de saúde e bem-estar são solucionadas a partir de uma ação consciente e participativa, que se organiza com elementos específicos de sua história, sua cultura e sua dinâmica própria" (p.34)

A educação em saúde se presta, enfim, para instrumentalizar as populações na identificação dos problemas de saúde e analisar as causas e consequências em relação às práticas vividas nas comunidades. Desta forma, as instituições de saúde, especialmente aquelas ligadas à formação de profissionais, precisam pensar ações e gerenciar recursos humanos e institucionais para a implementação de estratégias que possam ser ferramenta para uma melhor 
qualidade de vida dos seus públicos. Uma das ferramentas para executar esse acompanhamento são as estratégias de comunicação.

Para Moreira, Nóbrega e Silva (2003), a comunicação em saúde é o estudo e o uso de métodos para informar e influenciar as decisões individuais e coletivas que melhoram a qualidade de vida do sujeito. As autoras ainda dizem que a comunicação em saúde tem a capacidade de aumentar o conhecimento e a consciência das questões, problemas e soluções de saúde; influenciar percepções, crenças, atitudes e normas sociais; demonstrar habilidades; mostrar os benefícios da mudança de comportamento; aumentar demandas de serviços de saúde; reforçar conhecimentos, atitudes e mudanças de comportamento; refutar mitos e concepções erradas; defender questões de saúde ou grupos populacionais; superar barreiras e problemas sistêmicos (MOREIRA; NÓBREGA; SILVA, 2003).

Um material bem escrito ou uma informação de fácil entendimento melhora o conhecimento e a satisfação do paciente, desenvolve suas atitudes e habilidades, facilita-lhe a autonomia, promove sua adesão ao tratamento, torna-o capaz de entender como as próprias ações influenciam seu padrão de saúde; e favorece sua tomada de decisão. É, portanto, uma forma de promover saúde e empoderar o indivíduo.

Araújo \& Cardoso (2007) propõem a expressão empoderamento, muito utilizada na comunicação popular em saúde, com o sentido de fortalecer os atores sociais para o exercício do seu poder cidadão, seja substituída na comunicação por 'apoderamento'. Para elas é uma referencia à “conviçção de que as pessoas adquirem poder quando elas tomam posse, se apropriam, se apoderam: dos meios de produção, de canais de circulação, dos conteúdos circulantes, das informações, de processos, de políticas, enfim" (ARAÚJO; CARDOSO, 2013, p. 217).

Nesse sentido, os educadores de saúde devem ter em mente que, para que as mensagens relacionadas com a saúde sejam eficazes, é necessário lançar mão de estratégias de comunicação. A ideia é que as mensagens sejam bem planejadas, precisas, relevantes. Diante disso, a educação e a comunicação em saúde podem ser vistas como estratégias de promoção da saúde; de conscientização individual e coletiva sobre a responsabilidade e o direito à saúde, estimulando ações que 
atendam aos princípios do SUS, de garantir a qualidade de vida do indivíduos, assegurando investimentos de forma igualitária para todos.

\section{Os produtos de comunicação em saúde do HUM}

O Setor de Comunicação do HUM, organizado em março de 2017, criou um conjunto de produtos para serem trabalhados diária e semanalmente, a partir das discussões sobre educação e comunicação em saúde, surgidas na Assessoria de Comunicação da UEM. Viu-se a necessidade de criar uma equipe específica para o hospital. Atualmente, o grupo é formado pela jornalista responsável, Ana Paula Machado Velho; em consonância com os gestores Elias Gomes de Paula, assessor de Comunicação da UEM, e Maurício Chaves Jr., superintendente do HUM. O grupo ainda contou com a ajuda das residentes em Jornalismo da Assessoria de Comunicação da UEM, Débora Arcanjo, que também contribuiu com o registro da experiência que está sendo relatada neste artigo. Atualmente o grupo se fortalece com a presença do Prof. Tiago Lucena e a estudante Lara Beatriz, do curso de Comunicação e Multimeios.

O trabalho começou, na verdade, dando conta das demandas diárias de eventos e de recepção de representantes dos veículos de comunicação de Maringá e região do HUM. Aos poucos, a equipe passou a pensar a realização de pautas sobre temas relevantes do Hospital. Foram feitas reportagens sobre o Ambulatório de Reumatologia, o Projeto de Extensão de Atividade Física desenvolvido em parceria com a UEM, entre outras produções. Com o sucesso da repercussão do trabalho, viuse a oportunidade de se ampliar a produção, o que se deu em 2018.

A ampliação foi definida depois de reuniões realizadas pela equipe. Colocou-se como meta aproveitar os canais de comunicação que a UEM já oferecia. Um deles é a Rádio Universitária $(106,9 \mathrm{FM})^{2}$, para a qual foi criado o programa Sintonia HUM, com objetivo de falar sobre a estrutura e as atividades do hospital em suas mais diferentes vertentes, dando voz a servidores técnicos, docentes dos cursos da área da UEM, que atuam no HUM, além dos alunos desses mesmos cursos e das residências oferecidas na instituição. 
O Sintonia é uma estrutura sonora de 15 minutos, que se divide em uma entrevista com um indivíduo responsável por um setor, por alguma pesquisa ou alguma ação escolhida para ser divulgada (13 minutos em média). Um dos seus blocos é intitulado "Papo Saúde" (2 minutos de duração) de carater informativo/educativo. Os temas abordados são definidos a partir da demanda de: eventos do hospital; datas comemorativas como o Dia do Enfermeiro, por exemplo; ou a apresentação mais focada de um setor específico e importante da instituição como o Banco de Leite. Estes temas são discutidos e definidos em reunião de pauta, realizada na última semana de cada mês.

São, enfim, produzidos, gravados e editados quatro programas por mês, com a veiculação de um por semana. Esses programas vão ao ar todas às terçasfeiras, às 15 horas, com reapresentação aos sábados, às 11 horas. No sábado, o arquivo é editado com a inserção de imagem com identidade visual do programa e após o upload fica disponível para acesso on demand. A média é de 208 visualizações por programa ${ }^{3}$.

O Facebook também veicula a postagem do Papo Saúde, o quadro que compõem o Sintonia. A equipe edita o quadro em separado e o posta nas quintafeiras, isoladamente, no formato de 2 minutos, promovendo movimento maior no canal de comunicação do HUM. A duração atende as caracteristicas próprias da navegação de usuários em redes sociais online que demandam conteudos mais curtos em sua duração (SANTAELLA, 2004).

Além disso, as entrevistas do Sintonia são transformadas em texto corrido para o site do HUM e da UEM. As conversas são degravadas e redigidas com o acréscimo de novas fontes. Por exemplo, a reportagem sobre o Protocolo do HUM, que foi veiculada no rádio tendo como fonte única a coordenadora do setor, no site, ganhou a participação do servidor responsável pelo trâmite de prontuários solicitados pelos pacientes, tarefa importante e, muitas vezes, controversa do Protocolo, visto que é um documento com informações extremamente pessoais que tem regras muito rígidas para a liberação. Desta forma, dá-se uma nova perspectiva de abordagem dos temas ao se inserir novas fontes ao processo informativo de formato impresso. 
A recepção ao material é monitorada pela equipe, em especial ao conteúdo vinculado nas redes sociais online, para qual se responde aos usuários que dialogam na plataforma.

Figura 01: Página do HUM no Facebook com a disponização dos episódios do Sintonia HUM.

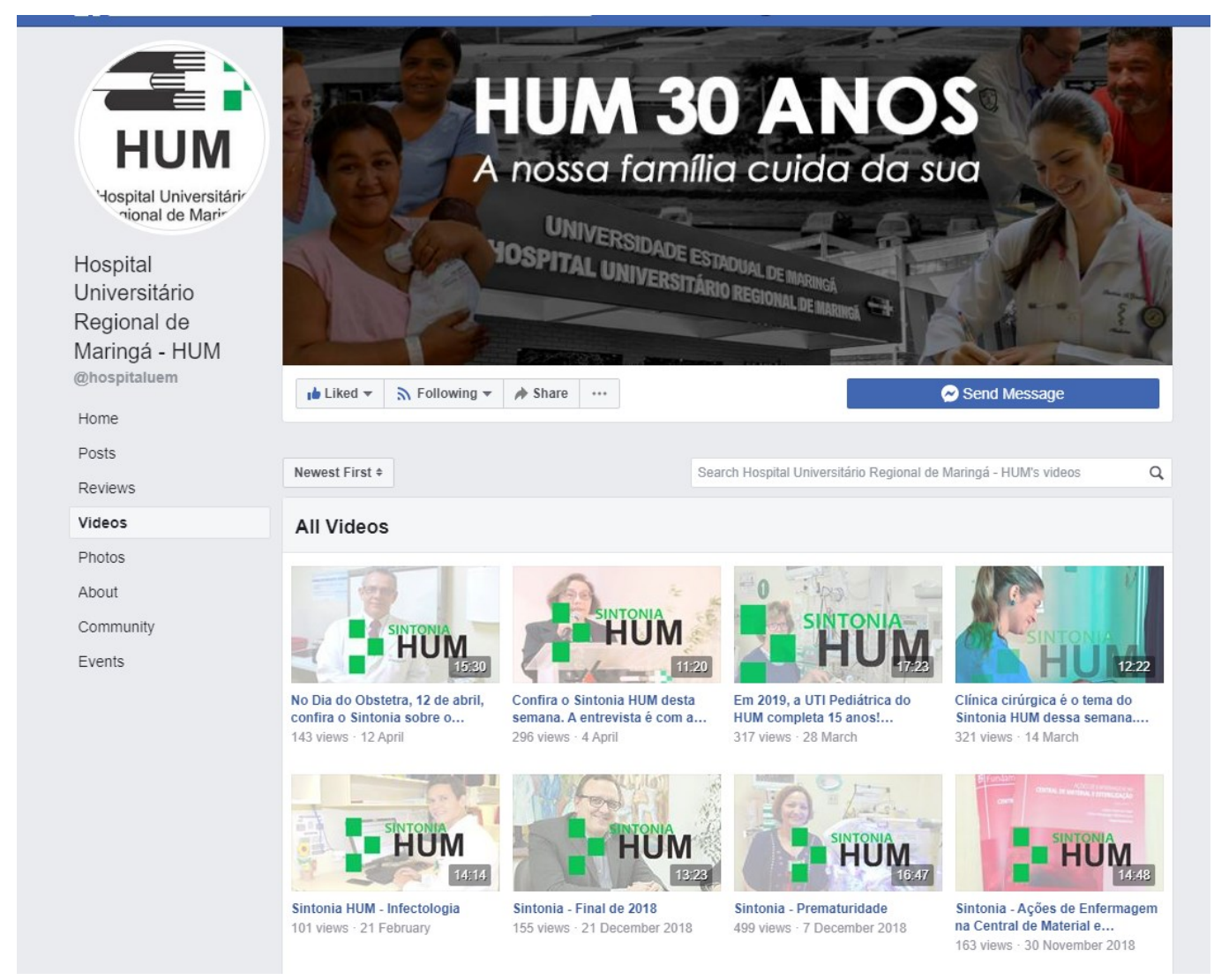

Quanto aos comentários e participações ainda percebeu certa timidez. As interações, em sua maioria, eram manifestadas por meio dos botões de reações do Facebook (likes, etc). No entanto percebemos duas categorias de interações nos comentários: gratidão e dúvidas. Em um dos exemplos, no episódio sobre prematuridade, uma mãe agradece a equipe que a atendeu e a sua filha (e que tem a imagem de uma profissional no banner de divulgação do episódio). A usuária compartilha foto atual da criança e descreve: “...Minha bebê ficou 29 dias aí na UTI...e falo com conhecimento...uma profissional impar!!! E uma sensibilidade...um humanismo...admirável!!! Obrigada!!! Pelo que fizeram pela minha pequena...essa é a Ísis hoje com 3 anos e 6 meses...Graças a Deus...e os cuidados dessa equipe maravilhosa". Noutro um estagiário agradece a 
oportunidade de aprendizado e completa: "Sinto orgulho de ter feito parte dessa equipe". O melhor exemplo de dúvida vem no entanto de usuária que questiona a informação que ouvira de que o SUS era gratuito: “...De onde ela saiu com essa SUS "grátis"??" O questionamento oportunizou que nossa equipe disponibilizasse um canal de comunicação para esclarecer a usuaria sobre o conceito de gratuidade do SUS.

\section{Considerações Finais}

Implementar o projeto de comunicação do HUM não foi tão fácil. Pode-se destacar, por exemplo, que o programa de rádio Sintonia é realizado nas dependências do Hospital e não nos estúdios da UEM-FM, o que, algumas vezes, compromete a qualidade técnica do produto. Mas a equipe optou pela viabilização do programa em detrimento da qualidade visto que, se tivesse que levar os entrevistados até a sede da rádio muitas das pautas não seriam realizadas por causa da dinâmica de urgência e cuidado de um Hospital, e até pela indisponibilidade dos servidores. Quando eles são abordados no próprio ambiente, sentem-se valorizados e aceitam gravar as entrevistas que, por sua vez, se tornam muito mais interessantes.

Além disso, um aspecto negativo começa a ser vencido com a sistematização de ações de comunicação no HUM: o relacionamento tenso entre a comunidade hospitalar com a imprensa em geral. A relação de um hospital que atende pelo SUS com jornalistas passa por momentos complicados, já que, na maioria das vezes, os veículos de comunicação procuram a instituição em momentos de crise e as matérias produzidas têm como foco muitas críticas. Porém, a presença do setor de comunicação nos corredores e as reportagens produzidas pela equipe vêm mudando esse panorama. Ao veicular fotos da comunidade do HUM, as reportagens internas vêm provocando um efeito muito bom entre os colaboradores do Hospital. Eles se veem como parte integrante e importante da instituição e da sociedade, criando uma aura positiva, uma alta autoestima entre o grupo. 
Em outras palavras, produzir conteúdo para o Hospital fez surgir uma efeito inesperado de endomarketing, visto que está permitindo a construção de um relacionamento bastante interessante entre a administração e os funcionários do hospital. Esse indivíduos, inclusive, passam a ser replicadores dos conteúdos veiculados pelos canais de comunicação do HUM, especialmente, nas redes sociais.

É certo que a iniciativa do projeto de comunicação do HUM é recente e não há, ainda, como mensurar, por exemplo, resultados sobre as ações educativas na área da Promoção da Saúde. Mas já estão agendadas no cronograma da equipe a realização de reuniões para que se possa realizar uma pesquisa de opinião com o público interno por meio da qual será possível definir estratégias que possam mudar hábitos e levar informações de empoderamento em saúdepara funcionários, estudantes e pacientes do Hospital.

\section{Referencias Bibliográficas}

ARAÚJO, Inesita Soares De; CARDOSO, Janine. Circulação polifônica: comunicação e integralidade na saúde. In: PINHEIRO, ROSENI et al. (Org.). . Construção social da demanda por cuidado: revisitando o direito à saúde, o trabalho em equipe, os espaços públicos e a participação. Rio de Janeiro: Editora do Centro de Estudos e Pesquisa em Saúde Coletiva - CEPESC, 2013. p. 211-224. https://doi.org/10.1590/s0102-311x1999000300005

ARAÚJO, Inesita Soares De; CARDOSO, Janine Miranda. Comunicação e Saúde. Rio de Janeiro, RJ: FioCruz, 2007.

BRASIL. Constituição $\quad$ Federal. Disponível em: <http://www.planalto.gov.br/ccivil_03/constituicao/constituicaocompilado.htm>.

BRASIL et al. Política Nacional de Promoção da Saúde: PNPS. . Brasília-DF: Ministério da Saúde. , 2015.

CGEE, Centro de Gestão e Estudos Estratégicos. Percepção Pública da C \& T no Brasil 2019 / Public Perception of Science and Technology in Brasil - 2019. . Brasília-DF: [s.n.], 2019.

Disponível em: <https://www.cgee.org.br/documents/10195/734063/CGEE_resumoexecutivo_Perce pcao_pub_CT.pdf $>$.

CLIFT, Kathy; RIZZOLO, Denise. Vaccine myths and misconceptions. Journal of the American Academy of Physician Assistants, v. 27, n. 8, p. 21-25, ago. 2014. https://doi.org/10.1097/01.jaa.0000451873.94189.56 
GONÇALVES, Gisela. Os hospitais são nossos amigos? Um estudo sobre o papel do Facebook na comunicação dialógica das organizações hospitalares. In: RUÃO, T.; NEVES, R.; ZILMAR, J. (Org.). . A Comunicação Organizacional e os desafios tecnológicos: estudos sobre a influência tecnológica nos processos de comunicação nas organizações. Braga - Portugal: CECS, 2017. p. 15-33. https://doi.org/10.5216/ci.v20i3.42398

GREENBERG, Joshua; DUBÉ, Eve; DRIEDGER, Michelle. Vaccine Hesitancy: In Search of the Risk Communication Comfort Zone. PLoS currents, v. 9, 3 mar. 2017. Disponível em: <https://www.ncbi.nlm.nih.gov/pubmed/28357154>. Acesso em: 5 set. 2019.

GRIFFIS, Heather M. et al. Use of Social Media Across US Hospitals: Descriptive Analysis of Adoption and Utilization. Journal of Medical Internet Research, v. 16, n. 11, p. e264, 27 nov. 2014. Disponível em: http://www.jmir.org/2014/11/e264/. Acesso em: 31 maio 2019.

MACHADO, Maria de Fátima Antero Sousa et al. Integralidade, formação de saúde, educação em saúde e as propostas do SUS: uma revisão conceitual. Ciência \& Saúde Coletiva, v. 12, n. 2, p. 335-342, abr. 2007. Disponível em: <http://www.scielo.br/scielo.php?script=sci_arttext\&pid=S1413-

81232007000200009\&lng=pt\&tlng=pt $>$. Acesso em: 3 set. 2019. https://doi.org/10.1590/s1413-81232007000200009

MERCHANT, Raina M.; ASCH, David A. Protecting the Value of Medical Science in the Age of Social Media and "Fake News". JAMA, v. November 1, p. 1-4, 19 nov. 2018.

Disponível em: <http://jama.jamanetwork.com/article.aspx?doi=10.1001/jama.2018.18416>. Acesso em: 20 nov. 2018. https://doi.org/10.1001/jama.2018.18416

MOORHEAD, S Anne et al. A New Dimension of Health Care: Systematic Review of the Uses, Benefits, and Limitations of Social Media for Health Communication. Journal of Medical Internet Research, v. 15, n. 4, p. e85, 23 abr. 2013. Disponível em: <http://www.jmir.org/2013/4/e85/>. https://doi.org/10.2196/jmir.1933

MOREIRA, Maria de Fátima; NÓBREGA, Maria Miriam Lima Da; SILVA, Maria Iracema Tabosa Da. Comunicação escrita: contribuição para a elaboração de material educativo em saúde. Revista Brasileira de Enfermagem, v. 56, n. 2, p. 184188, abr. 2003. Disponível em: $<$ http://www.scielo.br/scielo.php?script=sci_arttext\&pid=S0034-

71672003000200015\&lng=pt\&tlng=pt $>$. Acesso em: 3 set. 2019. https://doi.org/10.1590/s0034-71672003000200015

OLIVEIRA, Valdir de Castro. A comunicação midiática e o Sistema Único de Saúde. Interface - Comunicação, Saúde, Educação, v. 4, n. 7, p. 71-80, ago. 2000. Disponível em: $<$ http://www.scielo.br/scielo.php?script=sci_arttext\&pid=S1414-

$32832000000200006 \& \operatorname{lng}=\mathrm{pt} \& \mathrm{t} \operatorname{lng}=\mathrm{pt}>$.

https://doi.org/10.1590/s14142832000000200006 
ORNELLAS, Cleuza Panisset. Os hospitais: lugar de doentes e de outros personagens menos referenciados. Revista Brasileira de Enfermagem, v. 51, n. 2, p. 253-262, jun. $1998 . \quad$ Disponível em: <http://www.scielo.br/scielo.php?script=sci_arttext\&pid=S0034-

$71671998000200007 \& \operatorname{lng}=$ pt\&tlng=pt $>$. Acesso em: 4 set. 2019. https://doi.org/10.1590/s0034-71671998000200007

PADRO, Ernande Valentin Do; SANTOS, Adilson Lopes Dos; CUBAS, Marcia Regina. Educação em saúde: utilizando rádio como estratégia. Curitiba-PR: Editora CRV, 2009.

SANTAELLA, Lucia. Navegar no Ciberespaço - O Perfil Cognitivo do Leitor Imersivo. São Paulo - SP: Paulus, 2004.

SILVA, Gabriela Martins; RASERA, Emerson Fernando. A construção do SUSproblema no jornal Folha de S. Paulo. História, Ciências, Saúde-Manguinhos, v. 21, n. 1, p. 61-76, 14 ago. 2013. Disponível em: <http://www.scielo.br/scielo.php?script=sci arttext\&pid=S010459702014000100061\&lng=pt\&tlng=pt>. Acesso em: 1 jun. 2018. https://doi.org/10.1590/s0104-59702013005000012

SMITH, Katherine Taken. Hospital Marketing and Communications Via Social Media. Services Marketing Quarterly, v. 38, n. 3, p. 187-201, 3 jul. 2017. Disponível

em: <https://www.tandfonline.com/doi/full/10.1080/15332969.2017.1363518>. https://doi.org/10.1080/15332969.2017.1363518

SOARES, Laura Tavares. As atuais políticas de saúde: os riscos do desmonte neoliberal. Revista Brasileira de Enfermagem, v. 53, n. spe, p. 17-24, dez. 2000. Disponível em: <http://www.scielo.br/scielo.php?script=sci_arttext\&pid=S0034$71672000000700003 \& \operatorname{lng}=\mathrm{pt} \& \mathrm{tlng}=\mathrm{pt}>$.Acesso $\mathrm{em}: \overline{7}$ set. 2019. https://doi.org/10.1590/s0034-71672000000700003

WASZAK, Przemyslaw M.; KASPRZYCKA-WASZAK, Wioleta; KUBANEK, Alicja. The spread of medical fake news in social media - The pilot quantitative study. Health Policy and Technology, v. 7, n. 2, p. 115-118, jun. 2018. Disponível em: <https://linkinghub.elsevier.com/retrieve/pii/S2211883718300881>. Acesso em: 5 set. 2019. https://doi.org/10.1016/j.hlpt.2018.03.002

WOOD, Michael J. Propagating and Debunking Conspiracy Theories on Twitter During the 2015-2016 Zika Virus Outbreak. Cyberpsychology, Behavior, and Social Networking, v. 21, n. 8, p. 485-490, ago. 2018. Disponível em: <http://www.liebertpub.com/doi/10.1089/cyber.2017.0669>. Acesso em: 31 ago. 2019. https://doi.org/10.1089/cyber.2017.0669

Data Recebimento: 07/09/19

Data Aprovação: 30/09/19 
${ }^{1}$ Pesquisa realizada sobre a percepção pública da Ciência e Tecnologia no Brasil, empreendida pelo Ministério da Ciência, Tecnologia, Inovações e Comunicações (MCTIC) e o Centro de Gestão e Estudos Estratégicos (CGEE).

${ }^{2}$ De acordo com o site da Rádio, "a emissora opera 24 horas ininterruptamente. Até 2 de junho de 2016 operou na classe B1, com potência de 1KW. Com liberação da ANATEL, a partir de 3 de junho de 2016 passou a funcionar na classe $\mathrm{A} 3$, com potência de $6 \mathrm{KW}$, ampliando a área de alcance de um raio de 50 para $250 \mathrm{Km}$ ". Informação disponível no site: http://www.uemfm.uem.br/a-radio/historico

${ }^{3}$ Média feita somando as visualizações de todas as edições (39) no dia 30 de maio de 2019. Sendo o programa de numero 17 o de maior visibilidade maior visibilidade (1000) e o 24 com (65 visualizações). 